\title{
DISINTEREST, DISAFFECTION, AND PARTICIPATION IN PRESIDENTIAL POLITICS
}

\author{
Warren E. Miller
}

Undue emphasis on the decline of voter turnout in national elections and its interpretation as indicative of political malaise are likely to make for erroneous understanding of the American democracy. Evidence from studies of the national electorate conducted between 1952 and 1978 shows that the explanation for declining turnout is not to be found in commensurate diminution in political interest or involvement, or in a decreasing sense of civic duty, feeling of political efficacy or trust in government. Where patterns of change have coincided, further analysis indicates an absence of possible cause-and-effect relationships. The decline has been chiefly limited to those population sectors characterized by lack of interest or involvement in national partisan politics. The article concludes with a projection of likely developments in political participation, including turnout, in future presidential elections.

The level of voter turnout has become a biennial preoccupation of those concerned about the nation's political health. Since 1960, when some 64 percent of those eligible to vote went to the polls, there has been a continuous decline, with each succeeding election seeing a smaller fraction of the electorate turning out to vote. In recent years, the decline in the relative number of American voters has been linked with other signs of national political malaise. Even at the peak of voter participation there were occasional expressions of concern among those who compared the American experience with the notably higher

An earlier version of this paper was presented to the Conference on National Elections 1980: Continuity and Change in American Polities, Washington University, St. Louis, May 1980.

Warren E. Miller, Professor of Political Science and Director, Center for Political Studies, Institute for Social Research, The University of Michigan. 
turnout rates usually recorded in other western democracies, but now the erosion of partisanship and the apparently diminished role for the political parties have been joined with the precipitous decline in trust and confidence in government. They have all been taken to signal the consequences of alienation and indifference that are presumably weakening the foundations of mass political participation necessary for a vital democratic process. In sum, the decline in the proportion of citizens voting on election day has been taken by many observers as the final evidence that our electoral system is in trouble.

Commentaries that link these various indicators of political malaise and, as a consequence, see declining turnout as a forerunner of imminent change in our political system, are flawed on at least two counts. In the first place, the argument that growing disenchantment and disinterest have led to a rejection of the party system and a lack of enthusiasm for participation in electoral politics errs in assuming that the several trends are necessarily linked causally, with decreasing participation as the final reflection of a national malady. In the second place, the argument ignores many other important-perhaps more important-indicators of the sustained health and vitality of the American electoral process.

These errors are of practical interest because in times of crisis and rapid change, the need for accurate analysis and diagnosis is doubly important. It is not only necessary to increase our understanding of the nature of our political structures and processes; it is also vitally important to forestall errors of interpretation and judgment which could lead to misguided decisions by the nation's political leaders. With the accumulation of more and better evidence from social science research, there is also accumulating evidence of instances in which judgments about the mood of the public have been in error and, at times, have led to leaders' decisions that altered the course of political events. For example, it now seems clear that such judgments and decisions were a result of erroneous interpretations of early primary elections results in 1968. In that winter and spring 12 years ago, the nature of the response to Eugene McCarthy's presidential candidacy was badly misunderstood (Levitin and Miller, 1979). The New Hampshire vote for Senator McCarthy, as well as subsequent primary election results in settings like rural Wisconsin, were mistakenly attributed to unqualified support for his "dove like" opposition to the Viet Nam war. Subsequent analysis revealed that McCarthy received the plurality of his support from New Hampshire hawks, not doves, just as he received strong support from the conservative neo-isolationist farming communities in western Wisconsin. It is at least possible that if Lyndon Johnson had 
read New Hampshire as a demand for a tougher stand in Viet Nam he might not have resigned his bid for reelection so soon, and that Robert Kennedy might not have made his ill-fated decision to contest for the presidency that year because of an over-estimate of support for American withdrawal from combat.

With less drama, and much less political consequence, the national address by President Carter in July 1979 reflected a similar misunderstanding of the nature of changing American sentiment with regard to trust in government. In that instance, a very recent massive erosion of confidence in government felt by the minority Republicans slightly outweighed a clear upturn in confidence on the part of President Carter's fellow partisans in the Democratic majority (Miller, 1979). Unaware that his first two years in office had encouraged his supporters while striking despair in the hearts of his opponents, Mr. Carter interpreted the net result as an undifferentiated indication of the continuing general decline of trust in government, which had indeed marked the entire period from the mid-1960s through the election of 1976. His exhortation to Americans to have faith in each other and in his administration was at least curiously timed and may have done more to exacerbate the problem than to resolve it. In this instance as in the former, more thoroughgoing analysis of available evidence could have forestalled a misreading of public sentiment and an unwarranted adjustment of leaders' perspectives.

In the process of analyzing changes that are taking place in the world of politics, whether they are changes in approval given to national leaders or other changes in citizens' attitudes and beliefs, it is important to determine whether the observed changes really have the meaning and significance attributed to them. It is of equal importance to identify and distinguish changes that may be relatively episodic or ephemeral from those that may be of more enduring character. Where turnout is concerned, it may indeed be appropriate (given a modicum of concern for democratic values and the continued health of a democratic polity) to worry about the persistently low levels of voter turnout which distinguish elections in the twentieth century from those of earlier years; but, as we shall note shortly, more recent changes in the proportion voting, such as reflected in the decline in turnout from 1960 to 1976 , most likely constitute a quite different, and possibly quite limited, source of concern.

The unrelieved preoccupation with turnout figures as measures of the health of our national electoral process is too simplistic. It often reflects a rather primitive understanding of the complexity of politics in a nation such as the United States. The preoccupation often seems to 


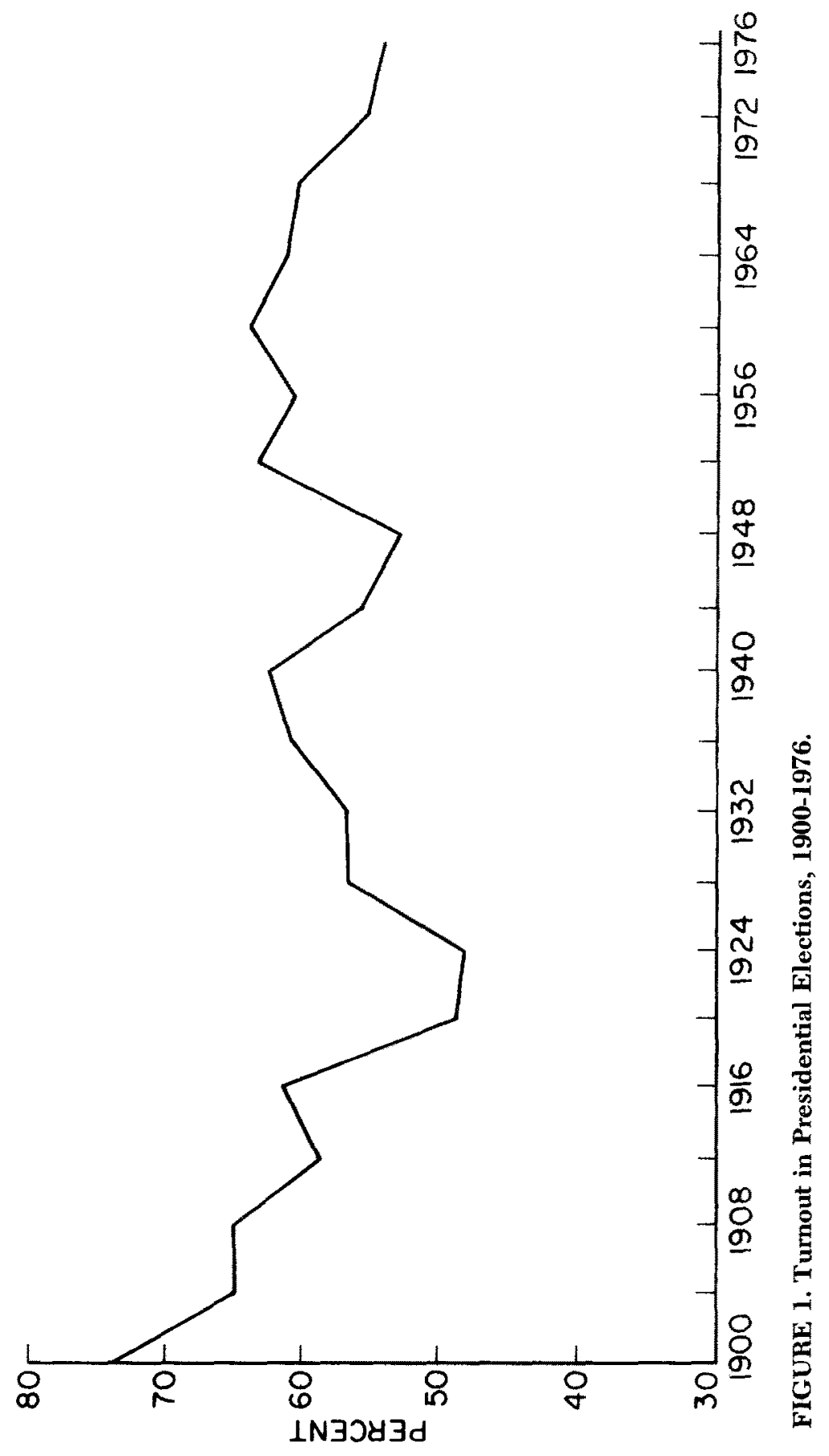


rest on placing unqualified emphasis on a kind of quantitative egalitarianism wherein each vote is considered equal to each other vote, but wherein it is not only assumed that more participation is better but that the sheer amount of voting is a sufficient test of the health of the system.

Informed political commentary should take a number of different perspectives into account in the assessment of nonvoting. From at least two perspectives, the relatively simplistic view of American politics does seem entirely appropriate for those interested in the well-being of democracy. First, if nonvoting in fact reflects alienation, and if increases in nonvoting are the result of active rejection of the political system, then an increase in an already high rate of nonvoting may indeed indicate or foretell systemic crisis. Even if nonvoting reflects only indifference, the problem may still be worrisome, but it may be more a long-range than an immediate problem. It is quite possible that indifference is a reflection of satisfaction, and the more satisfied the more indifferent and, therefore, the more nonvoting. Even if this is true, however, persistent nonvoting because of indifference may create a pool of nonparticipants who are inexperienced in the activities essential to democratic government. A reservoir of perennial nonparticipants may be a benign indicator in good times, but as the experience with the rise of totalitarian mass movements suggests, in the long run it may constitute a major problem for democratic government in times of dire or sudden crisis (Campbell et al., 1960:402-40).

From other perspectives, a concentrated focus on the score card of sheer numbers alone is seriously misplaced. For example, Richard Boyd (1980) has recently suggested that turnout in national elections should be appraised in the broader context of all American elections. The continued growth of governmental units, particularly at the local level, has brought a substantial increase in the numbers of opportunities Americans have to go to the polls. Therefore, the assessment of a decline in turnout for any given class of elections must clearly take account of the fuller context provided by the total universe of elections. Boyd's argument, rather persuasively documented, is that participation in all forms of elections has in fact steadily increased. However, given a relatively constant level of citizens interest in politics, a trade-off may be involved insofar as voting in national elections is concerned. As a consequence of the proliferation of local contests, national elections absorb less of the voters' energies and therefore witness a decline in turnout. With the "de-coupling" of state and local elections from the presidential elections-with more of the former held in nonpresidential years-voting in presidential elections may have decreased con- 
comitantly with increased voting in local governmental elections and on all manner of referred questions of public policy, particularly questions concerning taxation and governmental finance.

From yet another quite different perspective, the single-minded interest in turnout in national elections as the prime indicator of the health of the polity has long seemed anomalous. Political analysts never do as well in accounting for the difference between voters and nonvoters as they do in accounting for the difference between Democratic and Republican voters. In our usual attempts to account for a given level of turnout in a presidential election, the basic problem seems to be that many people vote without having any very good or obvious reason for doing so. The proportion of voters consistently runs much higher than the proportion of people who care how the election comes out, or who are informed about partisan alternatives, or who articulate any particular reason for going to the polls. Among the interested and informed segments of the population, voting turnout is always understandably very high. But among the largely disinterested and uninvolved, there is always a substantial cadre who nevertheless do turn out and participate even though, by any model of rational behavior, the evidence suggests their choice should be to abstain. Turnout, in other words, has always been such an ambiguous indicator of interest or involvement on the part of the citizen that the real challenge has been to explain why turnout is so high, not why it is so low.

There is yet another perspective which makes a single-minded interest in turnout even less persuasive. That perspective attends to all of the other forms of political participation engaged in prior to any election. Whether in response to invitations from political leaders who seek out constituents' opinions, or whether as a consequence of selfgenerated desire to voice one's opinions or demands, large numbers of citizens do in fact engage in a wide variety of political activities that are often more certain and less equivocal means of linking leaders with the led than is the simple act of casting a single vote. Even without a very highly differentiated or sophisticated view of the political process, it seems reasonable to pay attention to the full variety of actions that, in addition to the vote, connect political leaders to the electorate. For example, one may deplore the fact that voting turnout dropped 7 percentage points between 1964 and 1976, but one might also take heart from knowing that the proportion of the public engaged in writing letters to public officials increased by 65 percent (up 11 percentage points from 17 percent to 28 percent) in the same period. It is true that 9 percent fewer of the eligibles turned out in 1976 than voted in the first Stevenson-Eisenhower election in 1952; it is also true that the number 
of citizens who voluntarily attempted to persuade others to vote for the candidate or party of their choice increased by exactly the same amount during the same period. It would also seem important to recognize that the proportion of the electorate voluntarily making financial contributions to one's preferred party or candidate increased by 12 percentage points between 1952 and 1976, while turnout was dropping 9 points (and while the 16 percent who contributed in 1976 marked an "all time high" over the past quarter century, it is probably an underestimate of contributors; the figure undoubtedly misses many citizens who used the voluntary "checkoff" option on their income tax returns).

More generally, while turnout in national elections has dropped consistently from 1960 on, the proportion of the electorate which has turned out to vote on election day and which has also engaged in some other form of electorally relevant participation has remained virtually unchanged across the 16 year span from 1960 to 1976. From this perspective it seems not unreasonable to conclude that while the sheer proportions of those voting may have declined, the overall quality of national political participation improved between 1952 and 1960 and has remained constant during the ensuing years of declining turnout.

\section{EXPLAINING TURNOUT}

Given the importance of the many different modes of electorally relevant participation, it seems desirable to shift our analytic attention away from the singular act of turnout to emphasize the more comprehensive set of acts that provide the full network of linkages tying political leaders to the electorate at large. Before doing so, however, it is worth returning momentarily to the questions of the role of disinterest and disaffection in the decline of election day turnout at the polls. First, there is substantial evidence that general public interest in politics and public affairs has not declined since 1960. In fact, self-declared interest in following politics and public affairs has increased rather markedly during this period. Second, throughout the same period the electorate's general sense of the civic obligation to vote has remained constant and has not declined. Third, personal sense of the efficacy of one's political activity has not matched the drop in election day voting. And fourth, the use of the mass media to follow politics and political campaigns also has not diminished at all during the period of declining turnout.

The apparent anomaly created by the persistence of widespread political involvement in the face of decreasing participation at the polls is at least partly resolved when one examines turnout rates within 


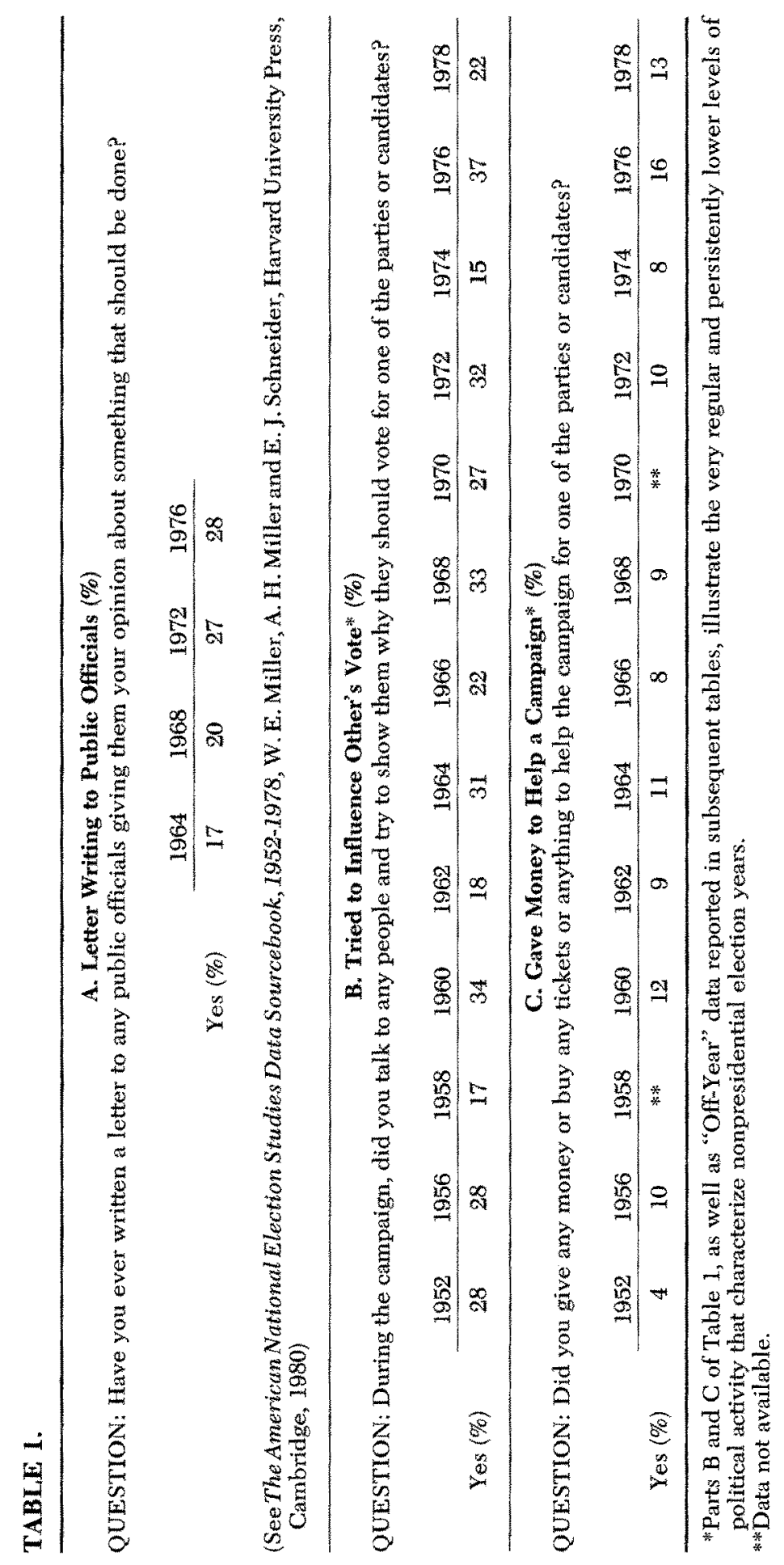




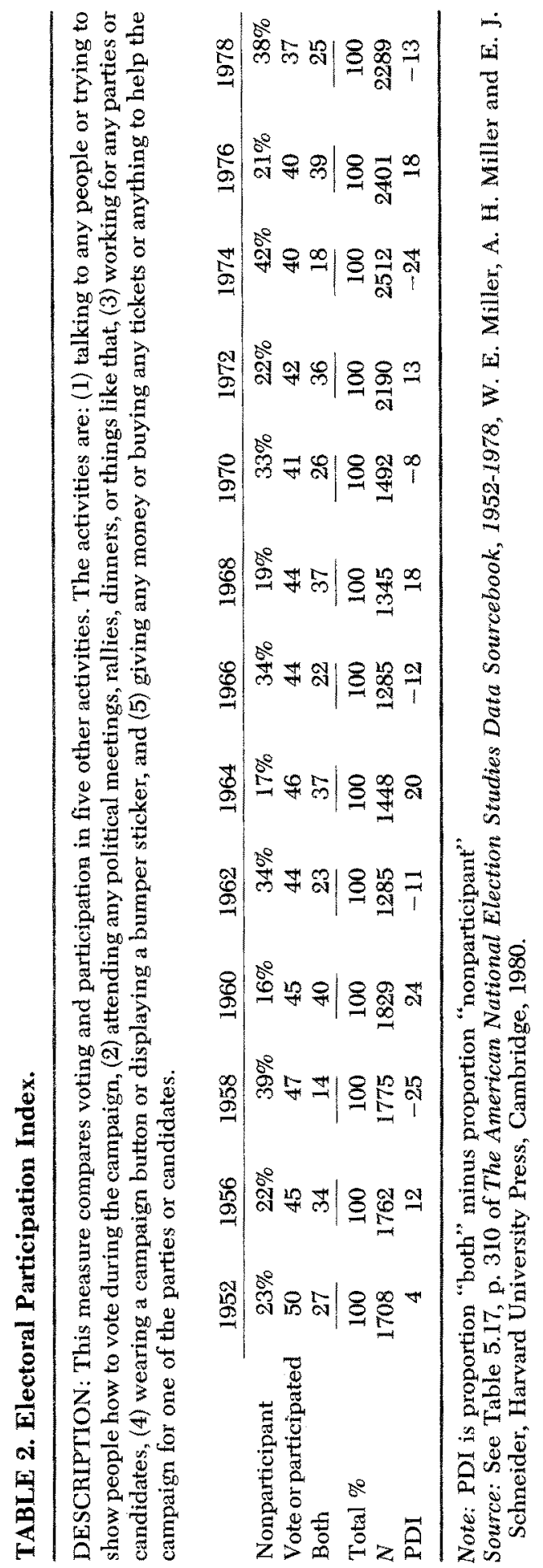




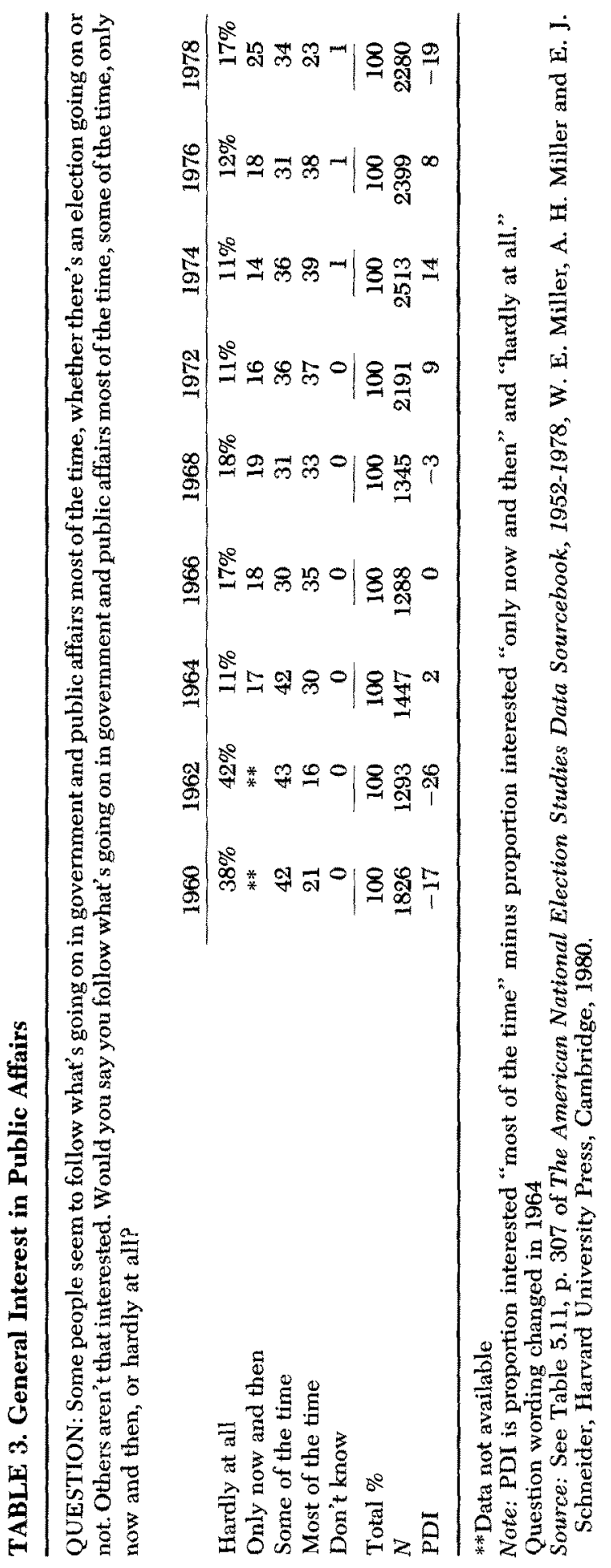




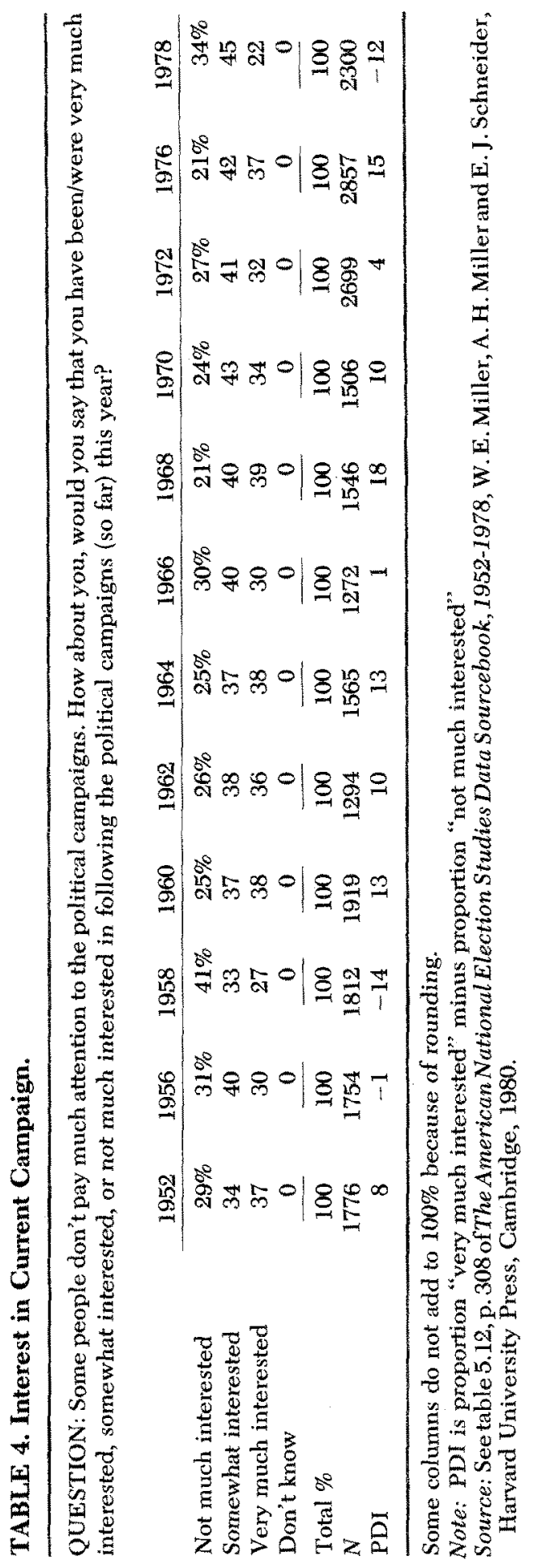




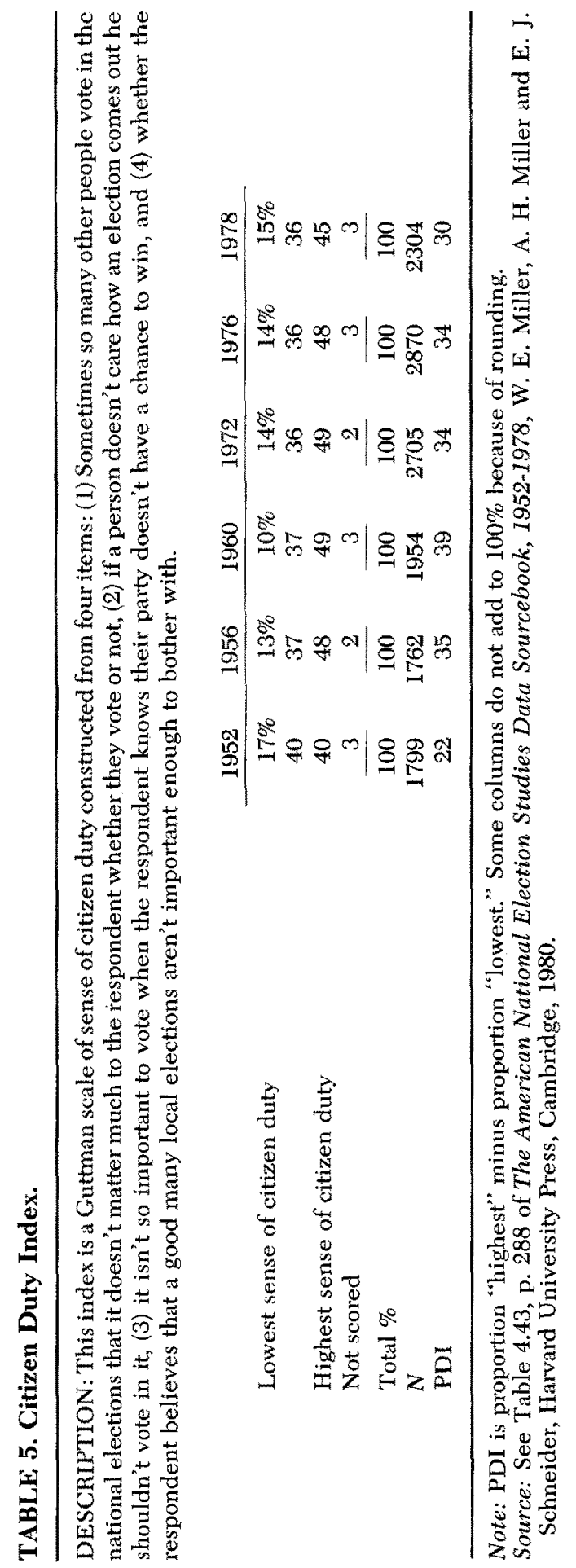




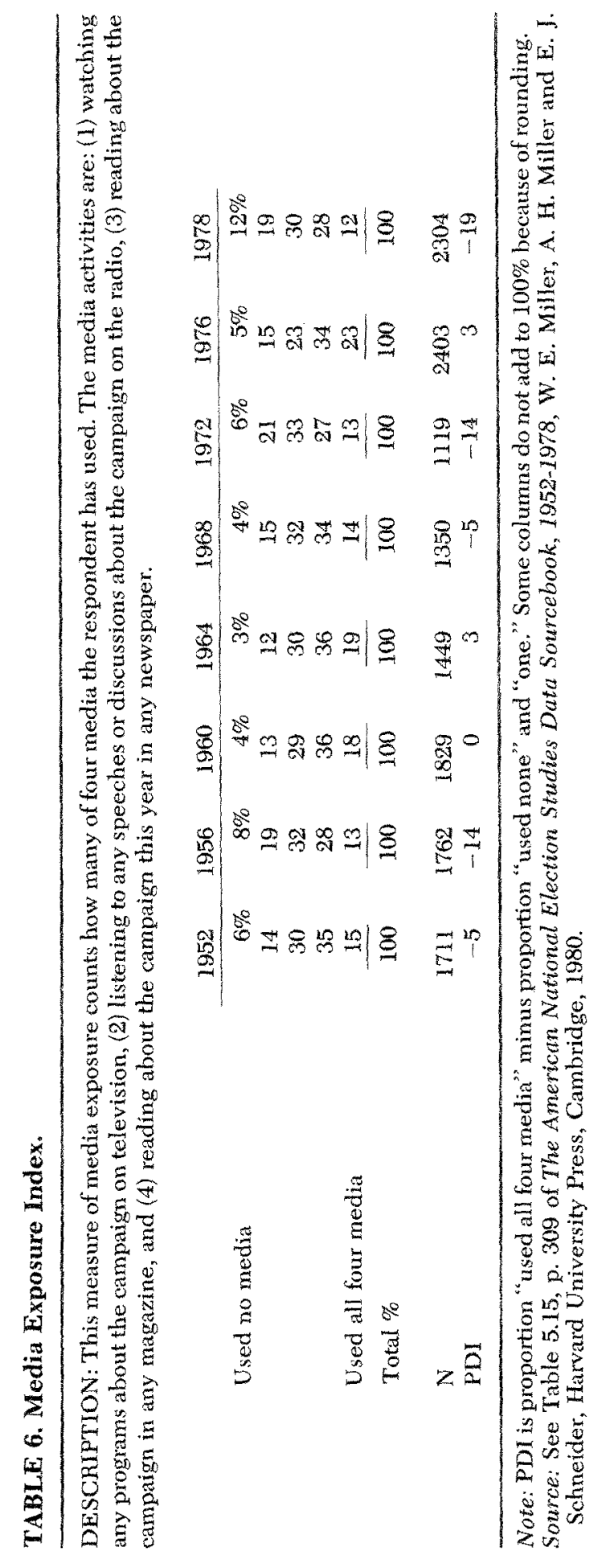


categories of political interest, civic duty, political efficacy, or media use. It becomes clear that the steady decline in turnout between 1960 and 1976 is matched primarily by the steady decline in turnout on the part of those who pay attention to public affairs "only now and then" or "never." On the part of those who report they are attentive "most of the time," there was a small drop in turnout between 1960 and 1964, but thereafter the turnout rate has remained virtually unchanged. The same is true where citizen duty is concerned. It is among those with the least sense of civic obligation to vote that there has been the sharpest decline in voting rates; turnout has remained at a high level among the persistently large group with the greatest sense of civic obligation. All of this suggests that the decline in election day voting has been concentrated very disproportionately in those sectors of the electorate in which one has always found the least political interest and a lack of sense of civic virtue, leaving the burden of voting more and more heavily with those who are committed to the democratic process and whose participation maximizes its quality.

A sharper and perhaps more insightful view of the actual process of short-term demobilization is suggested by an analysis of the relationship between voter turnout and strength of partisan identification. The explication of this specific analysis rests, in turn, on a somewhat more complex analysis that addresses, in the first instance, the nature of declining partisanship within the electorate. The details of that analysis are presented elsewhere, and for the present purposes it is enough to review the major conclusions (Miller and Miller, 1977). One of the more fallacious conceptions about contemporary American politics holds that there has been a wholesale rejection of partisanship on the part of former party loyalists and one-time party identifiers. It is undeniable that the national distributions of party identification have shifted markedly over the past few decades. Today there are fewer citizens with a sense of strong partisanship than in the early 1960s. There has also been a substantial increase in the proportion of citizens who think of themselves predominantly as independents, although the change in proportions of those who persistently deny any sense of partisan preference has been much less dramatic than many commentaries would lead one to expect.

A reduction in the proportions of strong partisans and an increase in the proportion of nonpartisans would necessarily imply that partisans have chosen to become nonpartisans only if there were no change in the composition of the electorate. In point of fact there has, of course, been a substantial change in the composition of the electorate across the same years in which the aggregate decline in partisanship has been 


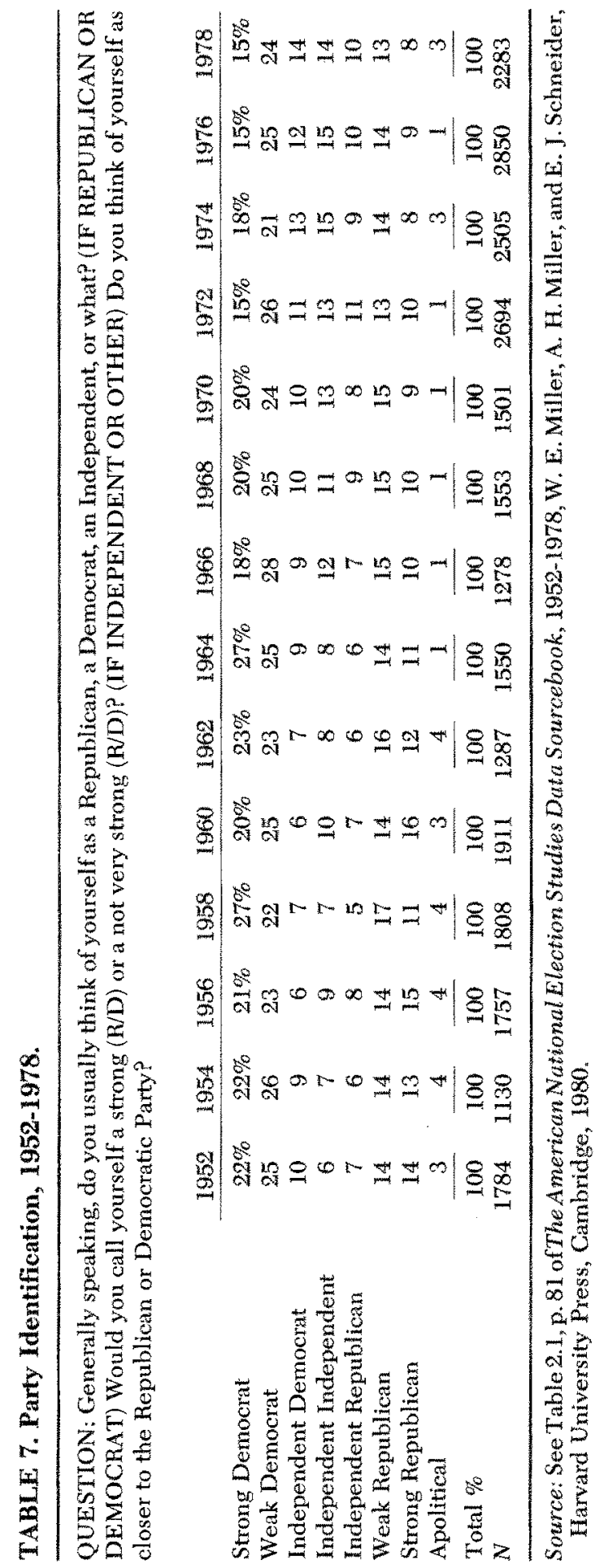


noted. A disaggregation of each year's electorate into four-year cohorts (composed of those who have in common the date of their first eligibility to vote in a presidential election) immediately discloses that most of the change in partisanship has been the result of the young replacing the old. Beginning in 1968, but most noticeably in 1972 and 1976, the new cohorts entering the electorate were much less partisan, and more often totally devoid of partisan preference, than their counterparts of earlier years. At the same time, the old cohorts (whose numbers of active voters were declining through very real mortality) contained the largest of proportions of strong partisans. The replacement of the old with the young accounts for the overwhelming porportion of the decline in partisanship noted in the succession of national distributions of party identification across the years. The rejection of partisanship by one-time partisans accounts for no more than one-fifth of the net decline in partisanship portrayed in Table 7. This fact is important on two counts. First, it leads to the rejection of the hypothesis that the decline in partisanship has been largely a function of a rejection of partisanship as party loyalists have changed to political independents. This, in turn, suggests a rejection of the hypothesis that declining trust in government, which has occurred uniformly across all age cohorts, has been either a cause of or caused by the rejection of partisanship.

The change in partisan topography-and the magnitude should not be overestimated-is most reasonably and parsimoniously interpreted as the consequence of an antipolitics, antiparty era which had a major impact on the politicization of young citizens without causing a major disruption in the partisanship of the established voters. The impact of the period of the New Politics of a decade ago was very real, and this impact has left a "generational" scar on the polity.

An inspection of turnout rates within categories of partisanship across the 1950s, 1960s, and 1970s reveals patterns that are consistent with this compositional interpretation of generational changes in the nation's partisanship. If a comparison is drawn between the Eisenhower era and the Carter election, turnout is in fact steady or higher for all categories of partisans except for the IndependentIndependents, where turnout declined by some 20 percentage points between 1956 and 1976. Taking 1960, the year of peak turnout, as the base, a comparison with 1976 turnout indicates no decline in turnout among strong partisans, a moderate decline among weak partisans, and a sharp decline among Independent-Independents. These patterns are thoroughly consonant with the general conclusion that the decline in turnout has occurred primarily among the disinterested and uninvolved citizens and most sharply as a direct function of the entry into 


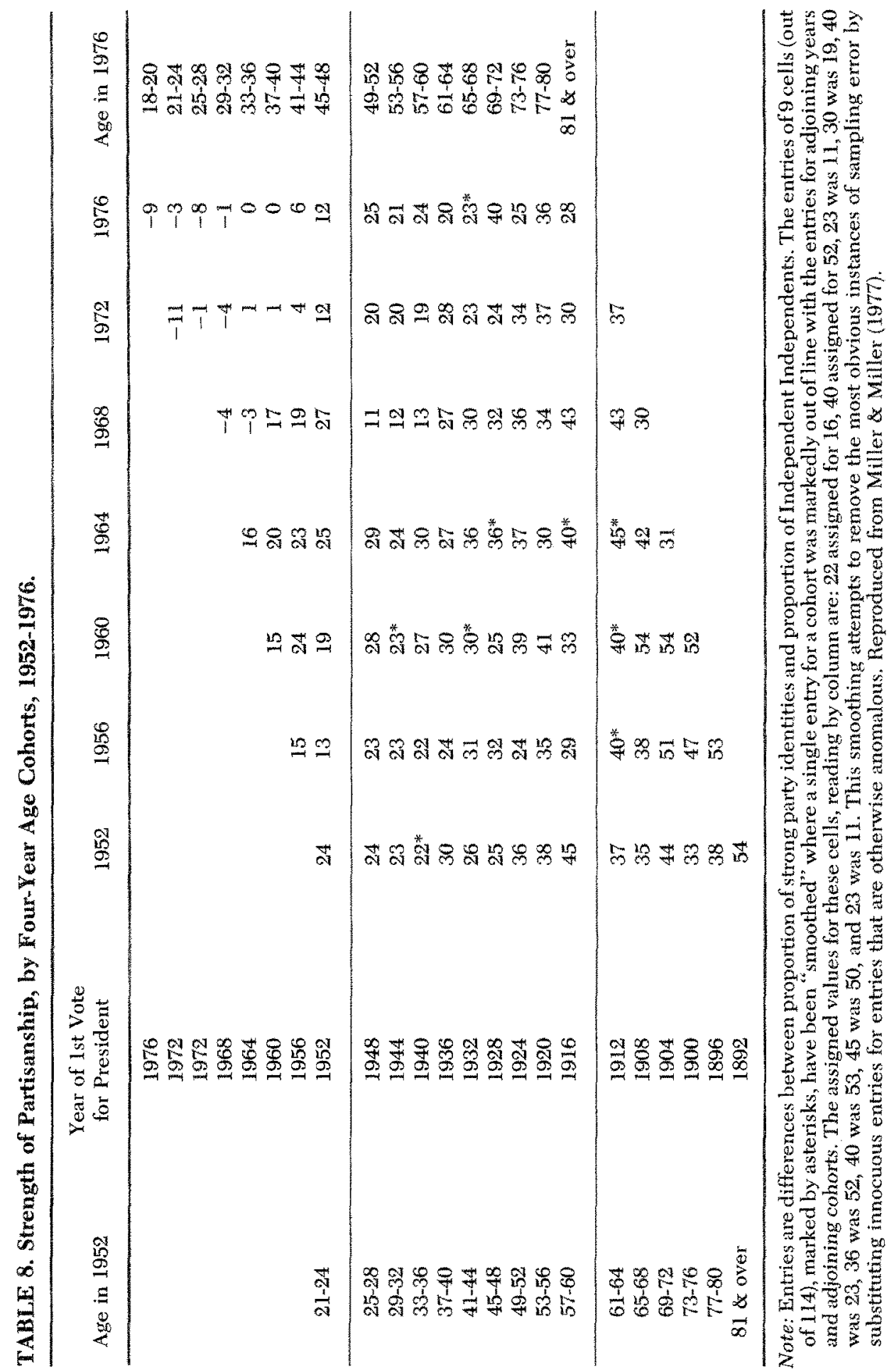


the electorate of younger citizens who lack a sense of engagement in the partisan politics of the nation (see Beck, 1974). It is only among the poorly educated, those with low incomes or with other attributes of low socioeconomic status, or among those least informed about or least engaged by the national partisan competition, that one observes alarming declines in voting turnout.

A final piece of evidence that separates the alleged nationwide increase in alienation and disaffection from the coincident decrease in turnout is provided by a replication of an analysis first completed following the 1976 elections (Miller and Miller, 1977). Table 10 below replicates that analysis across the past four elections. The general conclusion seems unmistakable. Once one takes account of the interrelationships among trust in government, sense of political efficacy, and turnout, it is evident that lower turnout is not at all associated with lower degrees of trust or increased cynicism. Indeed, on the average, across the eight comparisons that can be made of turnout rates for citizens distinguished by having high or low trust, turnout is a fraction of a percent higher for those exhibiting lesser degrees of trust. (Sense of political efficacy is equally uniformly a strong correlate of the propensity to vote.)

The explanation for declining turnout is not to be found in commensurate declines in political interest or involvement, or in a decreasing sense of civic duty, feelings of political efficacy, or trust in government. Few of these indicators of citizen commitment to political action have themselves changed to match the decline in turnout, and where the patterns of change have coincided, further analysis indicates the total absence of possible cause-and-effect relationships. To understand the drop in turnout, we must come to understand why the major decline has been limited to those sectors regularly characterized by lack of interest or involvement in national partisan politics. In sum, declining turnout cannot be attributed to an aggregation of decreased individual commitments to democracy because none of the general indicators of interest in politics show a parallel decline. Moreover, the decline in turnout has not taken place as a consequence of declining trust or increased alienation; there is simply no direct causal link between attitudes of trust in government and the decision to vote.

It is worth noting that the drop in turnout is not a consequence of changes occurring with regard to sex roles or the de facto enfranchisement of those black citizens who were effectively barred from the polls in the 1950s and early 1960s. Between the Eisenhower elections and the elections of the 1970s; the female turnout rate is virtually constant, whereas that of male citizens accounts for all of the overall decline. 


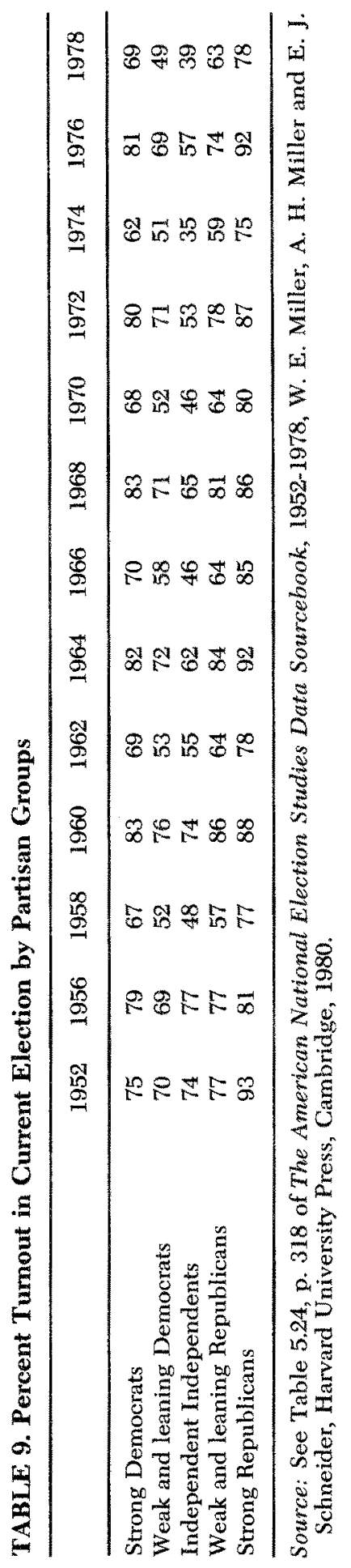




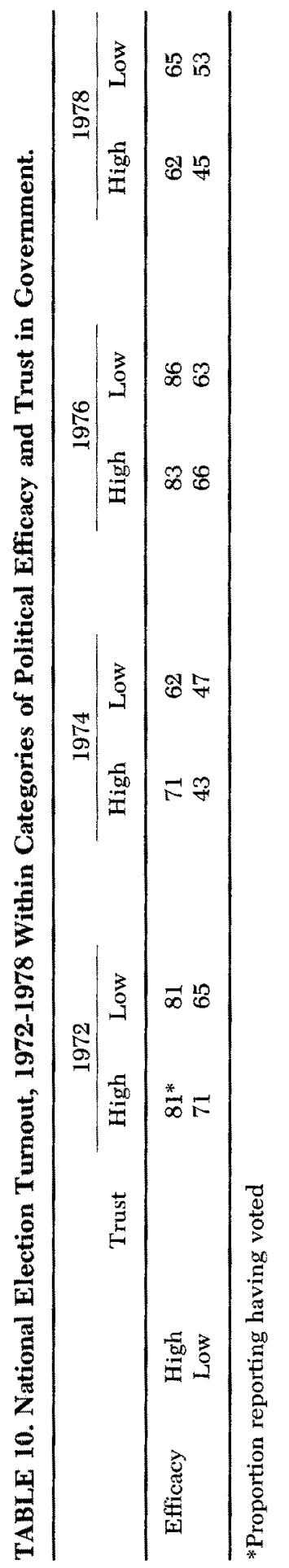


Across the same period it is white turnout that drops, more than offsetting a 30 point increase in black voting.

\section{ELECTORAL. PARTICIPATION IN THE YEARS TO COME}

A summary view of what we may expect in the way of political participation (including turnout) in future presidential elections can be evoked by reviewing three somewhat different sets of relevant factors. The first set of factors concerns social structure and social norms. Some aspects of changing age distributions, sex roles, educational levels, and racial equity are thoroughly predictable, and yet the intrusion of recent political events on the political significance of each of these factors makes prediction of the political consequences of their change less than certain; e.g., black mobilization may persist, and yet the outburst of black frustration and disillusionment in Miami in May 1980 indicates that black citizens cannot be taken for granted as regular participants in normally institutionalized electoral parties.

A second set of factors concerns analogous political structures and norms pertaining to party and participation. Here the problem of prediction is somewhat different. Legal barriers to participation are still in flux. Institutional support for partisanship is still undergoing change as a consequence of electoral reforms first introduced a decade ago. The proliferation of elections and possible increased use of the referendum may further complicate attempts to project rates of partisanship in national elections. It is difficult to predict future changes in partisanship and participation, because the institutions that sustain or enhance them are themselves subject to unpredictable changes in the near future.

Third, and finally, projections into the future must accommodate, if they cannot anticipate, the uniqueness of short-term factors that are more or less characteristic of every national election. Of course, candidates change, as $\mathrm{dc}$ the salience and content of the issues around which their campaigns are organized. And even the most pervasive of longterm secular trends can be interrupted by unforeseen short-term social or economic events, as well as by the vagaries of our unique process of presidential candidate selection.

Turning to social characteristics first, one could look at the present age distribution of the population and conclude that turnout will inevitably increase in the near future. The wave of young entrants into the electorate has crested and is now rapidly receding. Over the next decade there will be fewer and fewer numbers in succeeding cohorts entering the electorate. As a consequence, the average age of the 
electorate will certainly increase, and, unless past regularities are disturbed, the increase in age will be associated with an increase in turnout. This could be all the more dramatic because of the relative size of the cohorts that entered in 1968, 1972, and 1976-particularly in 1972 with the lowering of the voting age. Barring future catastrophies of a magnitude resembling those that began with the Vietnam war and ended with Watergate, one might optimistically expect the rate of politization of these "New Politics" generations-now a growing proportion of the electorate-to be even more rapid while they are in their late twenties and early thirties than has been historically true of young adults. If this were to occur, the increase in rate of participation would be even steeper than the age/turnout curves generated from the 1950s and the 1960s would suggest, the generational differences in turnout that are now so apparent would be muted, and a rapid increase in national turnout rates would result. At the same time, the prediction of an upturn in voting as the young grow older may be thwarted if the scar of the New Politics era remains strong, and if large proportions of those now under 35 remain unpoliticized and outside the ambit of national partisan politics.

Changes in sex roles promise less dramatic change in the future, but there is reason to expect that the gap between male and female participation will continue to diminish. In the early 1950 s male participation ran some 11-12 percent above female. This was reduced to no more than 4-6 percent at the turn of the decade entering into the 1970s. As occupational opportunities for women increase, and as equality of the sexes spreads to the periphery of society, the remaining sex differentials now found largely in rural and working class sectors may well disappear and produce an overall gain in citizen turnout in the process.

Barring a sudden reduction in the desirability of education, the dramatic shift in educational level of the electorate that has occurred since World War II will continue as the young replace the old. Given the range of consequences associated with education, including the acquisition of skills necessary for issue-oriented voting and the acquisition of attributes necessary for social mobility, it is reasonable to expect larger and larger proportions of the electorate to have the personal resources and the social support necessary for high rates of social participation, including voting. However, the same personal resources may, as Shively (1979) has noted, reduce voter reliance on parties and further erode the parties' ability to influence voter turnout.

Racial differences in turnout have been virtually eliminated, although the relatively recent mobilization of many blacks is still reflected in a rather unusual volatility for black voting. A reasonable 
expectation would be that black turnout levels would stabilize on a par with those of white citizens.

All of these factors, supplemented by their correlates in the domains of occupation and income, may be expected to enhance citizens' sense of civic obligation, sense of political efficacy, and interest in the broader social world, including the world of politics. These attitudinal correlates of political participation have been strengthened rather dramatically over the past quarter century, and there is every reason to expect the direction of change, if not the rate of change, to persist into the future and, thereby, produce an increase in voting turnout.

Anticipation and projection are less certain as one comes closer to the political core of the electoral process. It seems plausible to expect that the remaining legal barriers to participation will continue to drop as better social bookkeeping permits such things as permanent personal registration without fraud. The growing movement toward national uniformity of the administration of elections will almost certainly facilitate rather than inhibit political participation.

On the other hand, the future of partisanship in American politics is much less clear. Much has been written on the deleterious impact of various electoral process reforms on the political party. Public finance of election campaigns, particularly at the state and local level, could be the latest in a series of changes that result in a catastrophic erosion of the foundations of partisan politics. If public funds are channeled directly to candidates for office, bypassing the party organization as is already the case in some states, the parties" abilities to influence candidate selection, campaign platforms and the mobilization of the vote may be severely curtailed. (Jones, 1980a and 1980b) The new technology of campaigning may, in conjunction with increased public funding and increased direct voter participation through primary elections, further undercut the public role of the political party. The evidence thus far suggests, moreover, that if such changes diminish citizens' sense of party involvement they are likely to be reflected in a diminution of willingness to turn out on election day.

In addition to the institutional regularities that may influence both inclination and ability to participate in party politics in the future, shortterm fluctuations of political circumstance may be expected to confound any specific prediction about future election participation. Expectations about the competitiveness or closeness of a race interact with perceptions that differentiate contending parties or candidates to influence voter turnout. The expectation of a highly competitive race between sharply different candidates is likely to increase both participation and turnout, where perceptions of impending landslide vic- 
tories or perceptions of insignificant differences between contenders is likely to work against engaging the interest of potential voters in participating in election campaigns and elections themselves (Ferejohn and Fiorina, 1979). While it does appear to be true that turnout is not a direct function of the relative combined attractiveness or unattractiveness of the candidates, most of the other attributes that distinguish one election from another do seem likely to influence participation in electoral activities (Weisberg, 1969).

In general, it seems appropriate to expect a continuation or even a modest increase in the present relatively high levels of informal participation. A resurgence of partisanship and occasions of close partisan competition would most probably promote a substantial increase in turnout. However, at the same time that changes in social structure and social norms facilitate a wide range of political action, it is also possible that turnout itself may continue its relative decline. Although the topic is appropriate to a more extended and more direct analysis than has been suggested here, it seems likely that American politics is undergoing a qualitative change that may differentiate, with increasing sharpness, those citizens who are advantaged by personal resources and social location from those who are disadvantaged in both personal and social domains.

It seems likely that the politics of tomorrow will be more heavily oriented by ideology and more sharply focused on issue voting. Issue voting, in turn, is enhanced by most of the long-term social trends just discussed, including increased levels of formal education and increased sensitivity to group demands such as are represented by the calls for racial and sexual equality. To the extent that this is true, the complexities of political decision-making will doubtless discourage many citizens who would have voted in a different era. For all that one may decry thoughtless reliance on the symbols of party, and affective response to the call to join in partisan conflict, the earlier dominance of party in national politics doubtless encouraged many otherwise relatively uninterested and uninformed citizens at least to turn out on election day. If the organizing symbols of party are submerged under the diverse appeals of relatively independent candidates, and if candidates argue about the existence and consequence of a Phillips curve based on the relationship between rates of inflation and proportions of unemployment, or the intricate problems of increasing energy supplies, or the complex problems involving the interaction between international trade and domestic industrial production, it seems reasonable to presume that the turnout rate among the disadvantaged will decline still further. Participation in the sectors that already participate 
at near maximum strength may be preserved, but at the expense of the quantitative egalitarianism which expects at least a high turnout rate on election day. Whether or not such a political future would serve the long-term needs of a system dedicated to representative democracy remains to be seen.

\section{REFERENCES}

Beck, Paul (1974). "A Socialization Theory of Partisan Realignment." In R. Niemi, The Politics of Future Citizens. San Francisco: Jossey-Bass.

Boyd, Richard W. (1980). "Structural and Attitudinal Explanations of Turnout." Unpublished manuscript, April 1980.

Campbell, Angus, et al. (1960). The American Voter. New York: John Wiley Reprint. Chicago: Chicago University Press, 1976. Chapter 15, "Agrarian Political Behavior," pp. 402-40.

Ferejohn, John A., and Morris P. Fiorina (1979). "The Decline in Turnout in Presidential Elections." Presented at the Conference on Voter Turnout, San Diego, California.

Jones, Ruth S. (1980a). "State Public Financing and the State Parties." In Michael J. Malbin, Ed., Parties, Interest Groups, and Campaign Finance Laws. Washington, D.C.: American Enterprise Institute for Public Policy Research, pp. 283-321.

(1980b). "The Partisan Impact of State Public Campaign Financing Laws: Collection and Allocation." Presented at the 1980 Annual Meeting of the Midwest Political Science Association, Chicago, Illinois.

Levitin, Teresa E., and Warren E. Miller(1979). "Ideological Interpretations of Presidential Elections.” American Political Science Review 73: 751-71.

Miller, Arthur H., and Warren E. Miller (1977). "Partisanship and Performance: 'Rational' Choice in the 1976 Presidential Election." Presented at the 1977 Annual Meeting of the American Political Science Association, Washington, D.C.

—_, Warren E. Miller, Alden S. Raine, and Thad A. Brown (1976). "A Majority Party in Disarray: Policy Polarization in the 1972 Election." American Political Science Review 70: 753-78. See also Miller, Arthur H. and Warren E. Miller (1976). "Ideology in the 1972 Election: Myth or Reality: A Rejoinder." American Political Science Review 70: 832-49.

Miller, Warren E. (1979). "Confidence in Government or a Crisis in Leadership?" Public Opinion 2: 9-15, 60.

—_ A. H. Miller and E. J. Schneider (1980). The American National Election Studies Data Sourcebook, 1952-1978. Cambridge: Harvard University Press.

Shively, W. Phillips (1979). "The Development of Party Identification among Adults: Exploration of a Functional Model.” The American Political Science Review 73: 1039-1054. 
U.S. Bureau of the Census (1975). Historical Statistics of the United States, Colonial Times to 1970, Part II, p. Y 1-47. Washington, D.C.: GPO.

(1978). Statistical Abstract of the United States, 1978. Washington, D.C.: GPO.

Weisberg, Herbert F. (1979). “The Validity of Voter Registration and Turnout Reports in Surveys." Presented at the Conference on Voter Turnout, San Diego, California. 